\title{
An Aerophotographic Observation of Convective Clouds in the Vicinity of a Cold Dome Center
}

\author{
By S. Matsumoto and K. Ninomiya \\ Meteorological Research Institute, Tokyo \\ (Manuscript received 6 May 1965, in revised form 21 June 1965)
}

\begin{abstract}
Aerophotographic survey was applied for the analysis of a remarkable meso-scale line disturbance which developed off the coast of Hokuriku District on 2 February 1964.

This paper consists of two parts, i.e. the revision on the method of aerophotogrammetry specially designed for the cloud analysis and its application to the meso analysis. It is found that this aerophotographic method is as useful for the meso-scale phenomena as the radar observation.

The existence of active cumulus convection towering as high as $5000 \mathrm{~m}$ or more is assertained, even in winter season, within the region of smaller scale disturbance which develops in the vicinity of a cold dome center.
\end{abstract}

\section{Introduction}

During winter time, the amount of precipitation over Japan is concentrated to her western coastal regions, among which Hokuriku District is well known as the world's snowiest place. Heavy and concentrated snowfall has often been observed and resulted in disastrous damages. This is undoubtedly a sea effect phenomenon related to the combined effect of air mass modification over the Japan Sea, cold vortex in the upper atmosphere, cumulus convection and meso-scale disturbances.

In order to study the mechanism of heavy snowfalls in Hokuriku District, the project observations have been organized since 1962, and photographic observations of convective clouds by means of an airplane have been considered to provide important informations concerning the above mentioned air mass modification, the cumulus convection and the meso-scale disturbances over the Japan Sea where any kind of observation has scarsely been made. As a matter of fact, Fujita and Byers (1960), Malkus (1961, 1964), Watanabe (1961) and others have already introduced the aerophotogrammetry to cloud observation and showed its availabilities in many interesting analyses. However, the method of analyzing photographs of cloud has just been developed and those materials seem not to be utilized effectively. The Section 2 is, therefore, devoted to the discussions on the improvement of photogrammetry.

It has been known that heavy snowfalls are quite often associated with the cold vortex in the upper atmosphere. The cold vortex which passed over Japan on 2 February 1964 gives an example with characteristic structure of somewhat smaller scale. We found very active convection clouds in the vicinity of its core. The pictures of those clouds were analyzed in detail by the method described in Section 2, and were coordinated with the radar observations and the self-recording materials of the weather stations. Finally the development of convective clouds will be discussed briefly in relation to the synoptic situation.

\section{A method of the aerophotographic analy- sis specially designed for cloud obser- vation \\ i) Outline of observation}

A series of pictures was taken simultaneous. ly by two camera systems, i.e. Wild RC-8 
for vertical camera and Nikon $\mathrm{F}$ for high-oblique camera, installed on an Aerocommander $680 \mathrm{~F}$ aircraft operating at the level of 6000 $\mathrm{m}$ with a true air speed of $100 \mathrm{~m} \mathrm{sec}^{-1}$. Super wide angle lenses were adopted for both cameras. High-oblique camera was mounted on the right hand side window with its optical axis perpendicular to the axis of aircraft having a dip angle of $30^{\circ}$ which is required to take the horizon in field of view.

Exposure interval was chosen to be $14 \mathrm{sec}$ so as to obtain the overlap of $70 \%$ for the vertical picture. The overlap of vertical picture and high oblique picture was about $20 \%$. Further details of observation will be described somewhere else (Heavy Snow Storm Research Group, 1965).

\section{ii) Objective method of the aerophotographic analysis for cloud observation}

Let us consider the case of vertical photograph for the first place. If the successive photographs overlap each other, the height of cloud can be estimated by applying the method of stereoscopic measurement. Although this method is familiar (see the text book by Merritt (1958)), it would be necessary to mention briefly the error caused by cloud movement.

The relation between the displacement of aircraft and that of the image point of the same cloud during the exposure interval $\Delta t$ is given by

$$
u \Delta t=U \Delta t+\frac{H-h}{f}\left(x_{2}-x_{1}\right),
$$

where $U$ and $u$ are the air speed of aircraft and the component velocity of a cloud parallel to the air speed respectively (see Fig. 1). $H, h$ and $f$ are the height of flight, the height of cloud and the focul length respectively. $x_{2}$ and $x_{1}$ are the successive coordinates of the cloud under consideration referring to the principal point as origin on the image plane. Since the speed of the cloud on the image plane $u^{\prime}$ is given by $-\left(x_{2}-x_{1}\right) / \Delta t$, we obtain the formula giving the height of cloud

$$
h=H+\frac{f}{u^{\prime}}(U-u),
$$

in which both of $h$ and $u$ are unknown para-
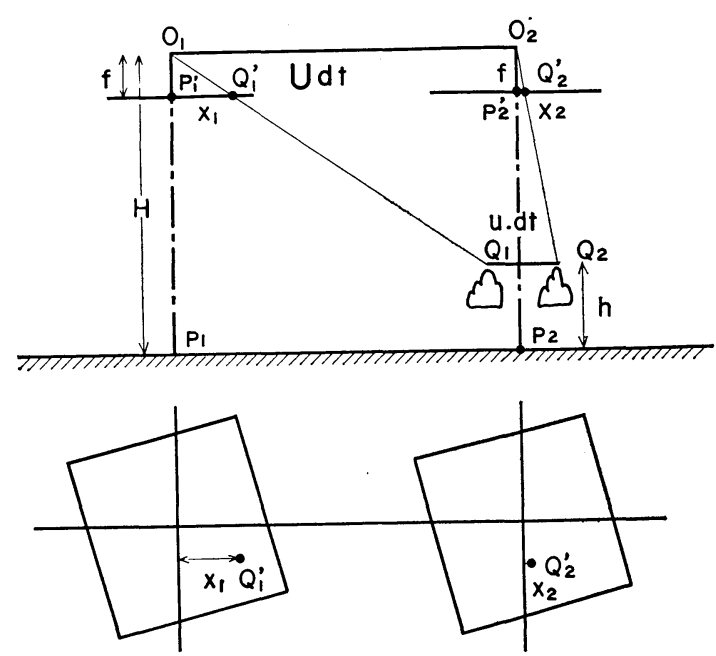

Fig 1. Geometry of aerophotogrammetry of cloud with respect to vertical photographs.

meters, and cannot be determined simultaneously by a single flight observation. Generally speaking, $u / U$ is a small quantity and the error of $h$ by neglecting $u$ is estimated to be of the order of $10 \%$.

For the measurement of $h$, a stereo-plotter, the ordinary optical apparatus of photogrammetry, is of course available under the same assumption.

It is considerably easy to estimate the height of cloud by means of serial vertical photographs. However, the area of coverage is limited to several $\mathrm{km}$ 's width just beneath the flight path. On the other hand, by means of high oblique photograph, we obtain informations from wider area ranging from several $\mathrm{km}$ to about $100 \mathrm{~km}$ away from the sub point. Deficit in this case is the difficulty of estimating the location and the height of a cloud, and it is likely to be more or less subjective.

Let us try to find a method suitable to deal objectively a number of high-oblique photographs. As shown by Watanabe (1961) and Fujita (1963), we have the following geometrical relationship between the object $Q$ and its image $Q^{\prime}(x, y)$ as is shown in Fig. 2.

$$
\begin{aligned}
& \varphi=\tan ^{-1}\left[\frac{x}{y \cos \eta+f \sin \eta}\right], \\
& \theta=\tan ^{-1}\left[\frac{y+f \tan \eta}{\cos \varphi(f-y \tan \eta)}\right],
\end{aligned}
$$




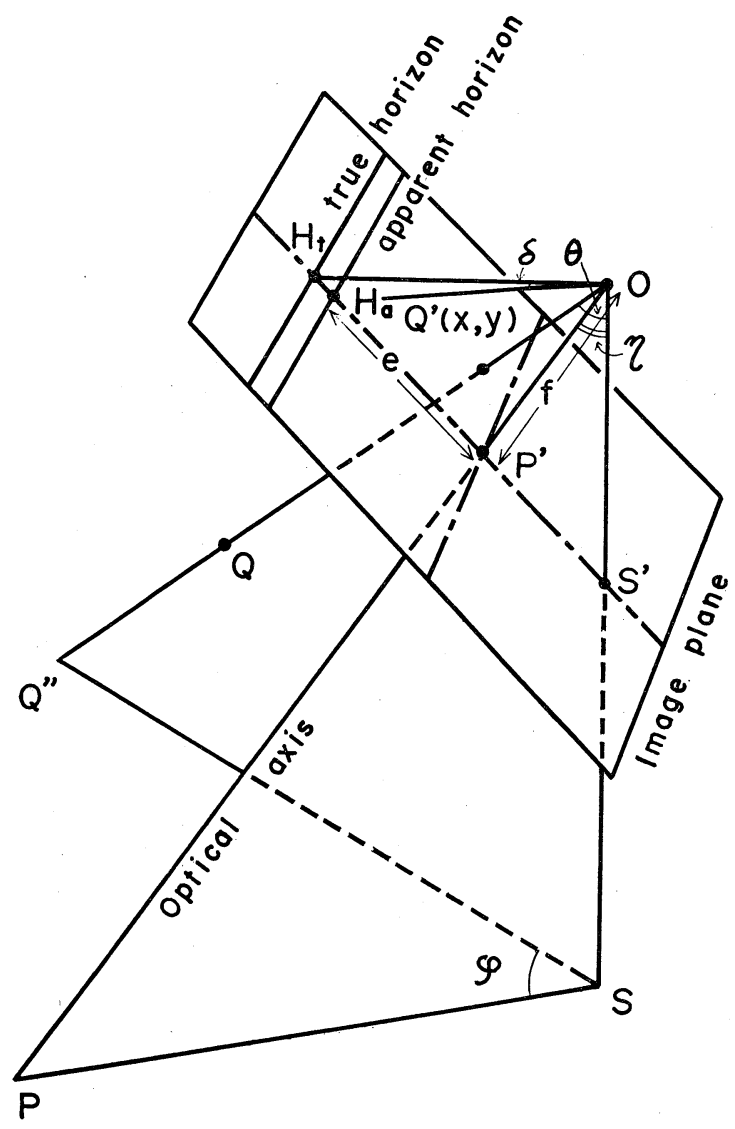

Fig. 2. Geometrical relationship between the object and its image on the high-oblique photograph.

where $\varphi$ is the azimuth and $\theta$ the nadir angle of the object and $\eta$ the tilt of optical axis. As to the coordinate on the image plane, $y$ axis is taken along the principal line, the principal point as the origin. Applying those equations alone to a single photograph, it is possible to obtain a rough idea concerning the cloud distribution when we can assume or estimate the cloud height somehow.

Even if the camera mounting is designed to obtain a fixed tilt of $60^{\circ}$, the actual tilt $\eta$ for each frame fluctuates according to the rolling of aircraft. Now $\eta$ is to be determined by the aid of apparent horizon of cloud as follows.

$$
\left.\begin{array}{l}
\eta=90^{\circ}-\delta-\varepsilon \\
\varepsilon=\tan ^{-1} e / f \\
\delta=\tan ^{-1} \sqrt{\frac{2(H-\bar{h})}{R}}
\end{array}\right\},
$$

where $e$ is the $y$ coordinate of the apparent horizon on the image plane, $\delta$ the vertical angle of apparent horizon and $\bar{h}$ the avarage height of the cloud constituting the apparent horizon. In determining $\bar{h}$ we can refer either to the above mentioned method by means of vertical camera or to the hypothetical value which may be obtained from the humidity observation of nearby radiosonde sounding. It is easily shown that the estimation of $\eta$ is not sensitive to the error of $\bar{h}$ since we have

$$
|\Delta \eta| \approx-\frac{|\Delta \bar{h}|}{\sqrt{2 R(H-\bar{h})}} .
$$

For the flight height of $6 \mathrm{~km}$, over- or underestimation of $\bar{h}$ as much as $1000 \mathrm{~m}$ makes an error no more than $1 / 4$ degree in the estimation of $\eta$.

The error in $\eta$ also causes errors in $\varphi$ and $\theta$ estimation as follows:

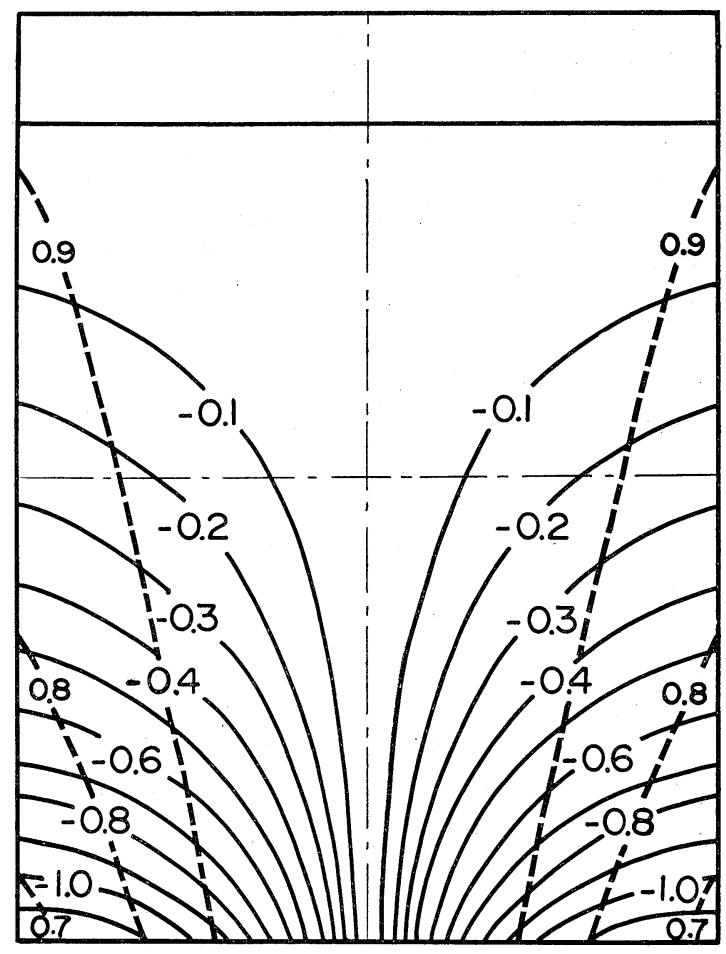

\section{focal length}

Fig. 3. The distribution of $\Delta \varphi$ (solid line) and $\Delta \theta$ (broken line) in degree on the image plane caused by 1 degree error of $\eta$ for the case of $\eta=60^{\circ}$. 


$$
\begin{aligned}
\Delta \varphi & =\sin ^{2} \varphi \frac{\frac{y}{f} \sin \eta-\cos \eta}{\frac{x}{f}} \Delta \eta, \\
\Delta \theta= & \frac{\sin ^{2} \theta}{\frac{x}{f}}\left[\frac{\cos \varphi\left(\cos \eta-\frac{y}{f} \sin \eta\right)^{2}}{\frac{x}{f}}\right. \\
& \left.+\sin \varphi\left(\sin \eta+\frac{y}{f} \cos \eta\right)\right] \Delta \eta .
\end{aligned}
$$

Fig. 3 shows, as an example, a distribution of $\Delta \varphi$ and $\Delta \theta$ on the image plane for our case of $f=21 \mathrm{~mm}, \eta=60^{\circ}$. We can conclude that this kind of error is negligibly small for our purpose.

For the measurement of cloud height, we have a direct method with high accuracy if the shadow of a cloud can be utilized in coordination of sun's astronomical data. However, in those area with denser cloud coverage such as in Hokuriku District, this method is applicable only for limited portion.

Finally let us describe our method of analysis based principally on the principle of parallax to which the least square technique is introduced.

The azimuth of a cloud under consideration changes with the movement of aircraft. An example is shown in Fig. 4. Obviously the change of $\varphi$ is larger for nearby clouds to the flight path. Taking into consideration all kinds of unavoidable fluctuation due to

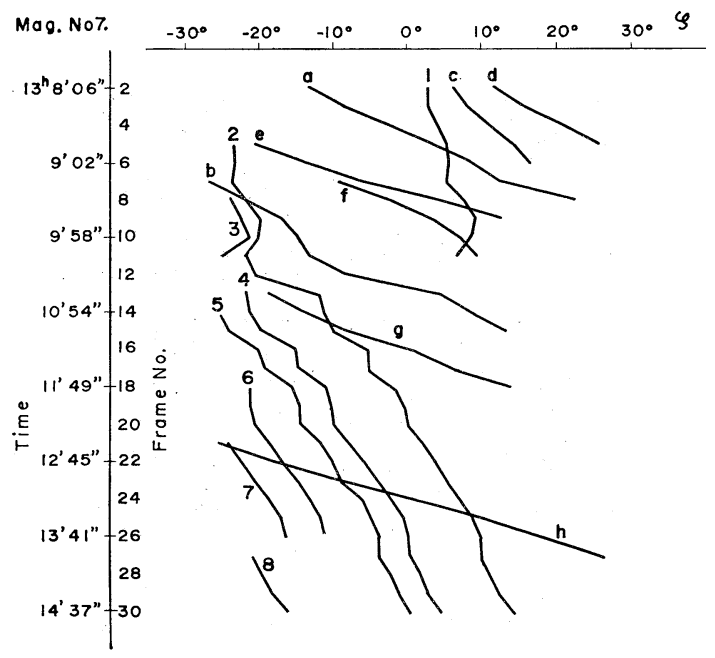

Fig. 4. The changes of the cloud's azimuth $\varphi$ with the movement of the aircraft steering of aircraft, we apply the least square technique to a series of photographs on which the same cloud appears. As is seen from Fig. $5, \tan \varphi_{i}$ of any object cloud changes linearly. Therefore the location of cloud $(X$, $Y$ ) which minimizes square deviation $S$ is obtained as follows.

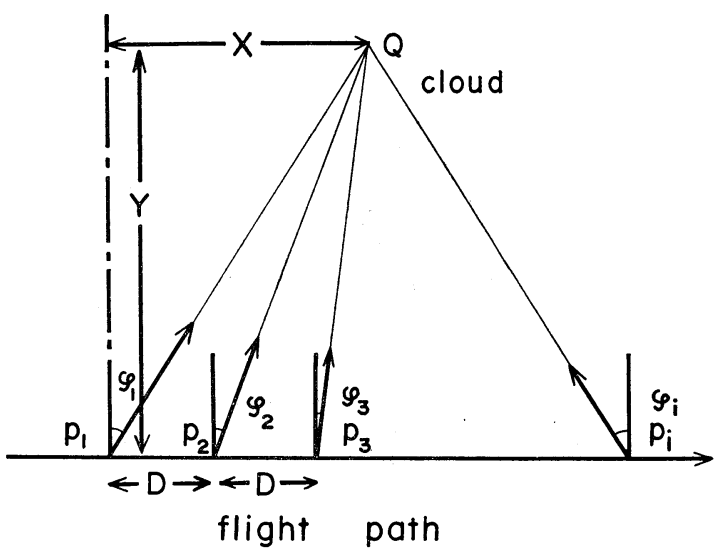

Fig. 5. Geometrical relationship between the change of $\varphi$ and aircraft movement.

$$
\begin{gathered}
S \equiv \sum_{i}\left(\frac{X-D i}{Y}-\tan \varphi_{i}\right)^{2}, \\
\frac{\partial S}{\partial X}=0, \quad \frac{\partial S}{\partial Y}=0,
\end{gathered}
$$

where $i$ indicates the number of exposures and $D$ the displacement of aircraft within successive time interval $\Delta t$. We obtain from eqs. (9) and (10)

$$
\begin{aligned}
& Y=-D \frac{\bar{i} \cdot \bar{i}-\overline{i^{2}}}{\overline{\tan \varphi_{i}} \cdot \bar{i}-\overline{\tan \varphi_{i} \cdot i}}, \\
& X=Y \cdot \overline{\tan \varphi_{i}}+D \bar{i},
\end{aligned}
$$

where bars indicate the average over the number of exposures to be used. The height $h$ is given by

$$
\left.h=H+\frac{\overline{r_{i}^{2}}}{2 R}-\overline{\frac{r_{i}}{\tan \theta_{i}}}\right)
$$

where $r_{i}{ }^{2}=(X-D i)^{2}+Y^{2}$. The second term on the right side of eq. (13) showing the effect of earth's curvature is negligibly small if the cloud is located within a distance of the order of $50 \mathrm{~km}$.

Here again the movement of cloud is neglected. It can be easily shown that the error is of the order of $u / U$ as is mentioned for vertical photographs. 
Another source of error is the curvature of the flight path. However, a flight is usually consisted of turnings and almost straight flights which actually do not cause serious error. Turnings with smaller radius of curvature will easily be detected by the nonlinearity in the change of $\tan \varphi_{i}$.

Actual procedure in analysis is, at first, to measure $e$ (the distance between the apparent horizon and the principal point) and decide the tilt angle $\eta$ for each frame by using eq. (5), and next, to select significant clouds and measure their coordinates on the image plane. Then the locations and heights of clouds are obtained by computing eqs. (3), (4), (12) and (13) numerically. The number of frames which are incorporated to the least square computation is, on the average, 4 or 5 for nearby clouds (see e.g. $b$ and $g$ in Fig. 4) and 20 30 for farther ones (see e.g. 2 and 4 in Fig. 4) from the flight path.

\section{iii) Aviation path}

Navigation elements of aircraft such as airspeed, height, heading, location and so on are recorded at every 5 min's interval, which are also required for photogrammetrical analysis. Among them, the location of aircraft is fixed by means of ADF (automatic directional finder) at a certain time interval and has to be interpolated at every exposure time. The precision by this method is rather poor especially at some distance away from radio beacon stations. Furthermore, the location fixing by a known topography appearing on photographs is not applicable over those area either covered by clouds or without any identifiable objects. Under those circumstances it becomes quite necessary to incorporate all possible methods of checking data related to the location fixing.

The heading, for example, can be measured indirectly by photogrammetric methods. If the shadow of a cloud on the sea surface is found, the direction of the optical axis and therefore the heading are easily obtained by knowing the azimuth and elevation of the sun. They are also computed by the aid of sun's reflection on the cloud surface, which often appears on a flat surface of cloud layer. In Fig. 6 are shown the recorded magnetic heading together with estimated heading men- tioned above. Good agreement showing an evidence of reliability, at the same time, guarrantees the camera mounting as expected.

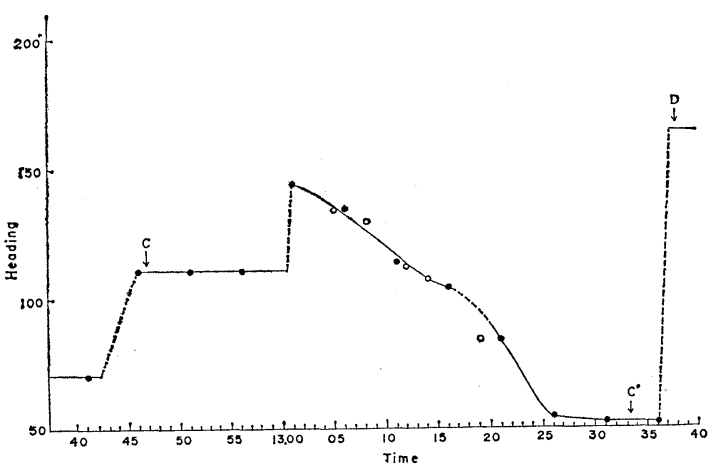

Fig. 6. True heading as a function of local time. Dark dotts are flight records in every $5 \mathrm{~min}$. White dotts are obtained by other informations such as sun's reflection or shadow of clouds. Letters show the position on the flight path given in Fig. 7.

Another information is the ground speed, which can be computed from the displacement of known objects, if any, such as buildings, rivers, roads and so forth appearing on the successive photographs. On the way back from our observation flinht, it just happened to see the identifiable ground surface through a cloudless area. The wind speed thus obtained as an difference between true air speed and ground speed coincides very well with the observed wind velocity at 15 JST.

Judging from those verifications mentioned above, it may be said that the reliability of the flight records becomes more evident. Thus making use of those flight records and the wind by rawinsonde observation wind at 15 JST, we composed the trajectory starting from the position where the object on the ground surface was identified (see Fig. 7).

\section{Convective activity and the line echo}

A considerable snowfall was observed in Hokuriku District in the afternoon of 2 February 1964 when an aerophotogrammetric observation flight was performed over the coastal area. Mosaic of the vertical photograph and a series of corresponding high oblique photographs are shown in the collected data published by the Meteorological Research Institute (1964). 


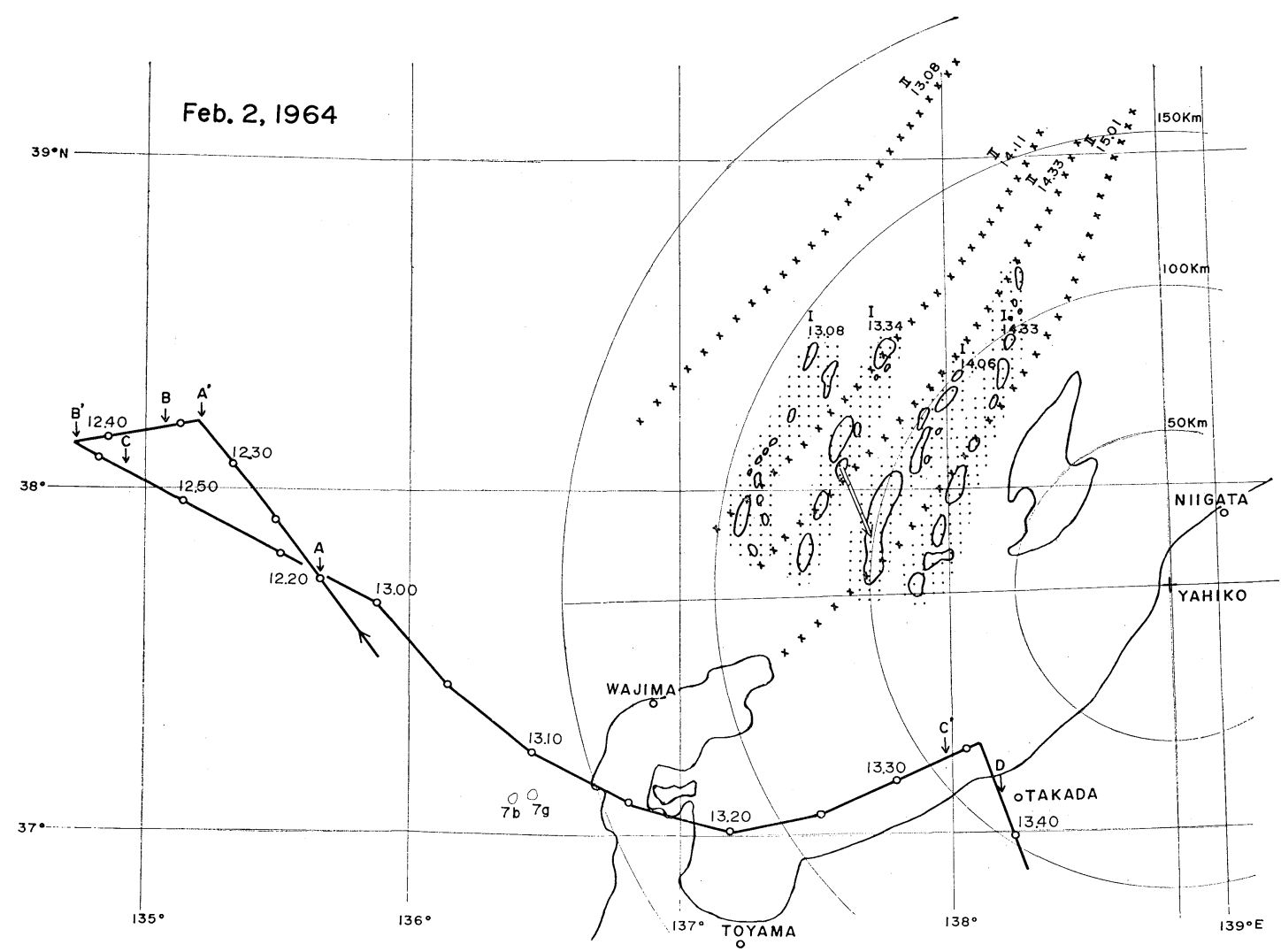

Fig. 7. Flight path labelled with local time. Composite radar echoes at about $30 \mathrm{~min}$. interval are also entered together with ranges from radar station (Mt. Yahiko). There are two systems of line echo, I indicated by stipples over rough sketch and II indicated cross symbols. Double arrow shows the displacement of a echo element. $7 \mathrm{~b}$ and $7 g$ indicate cloud identifications. See also Fig. 4 and Fig. 14.

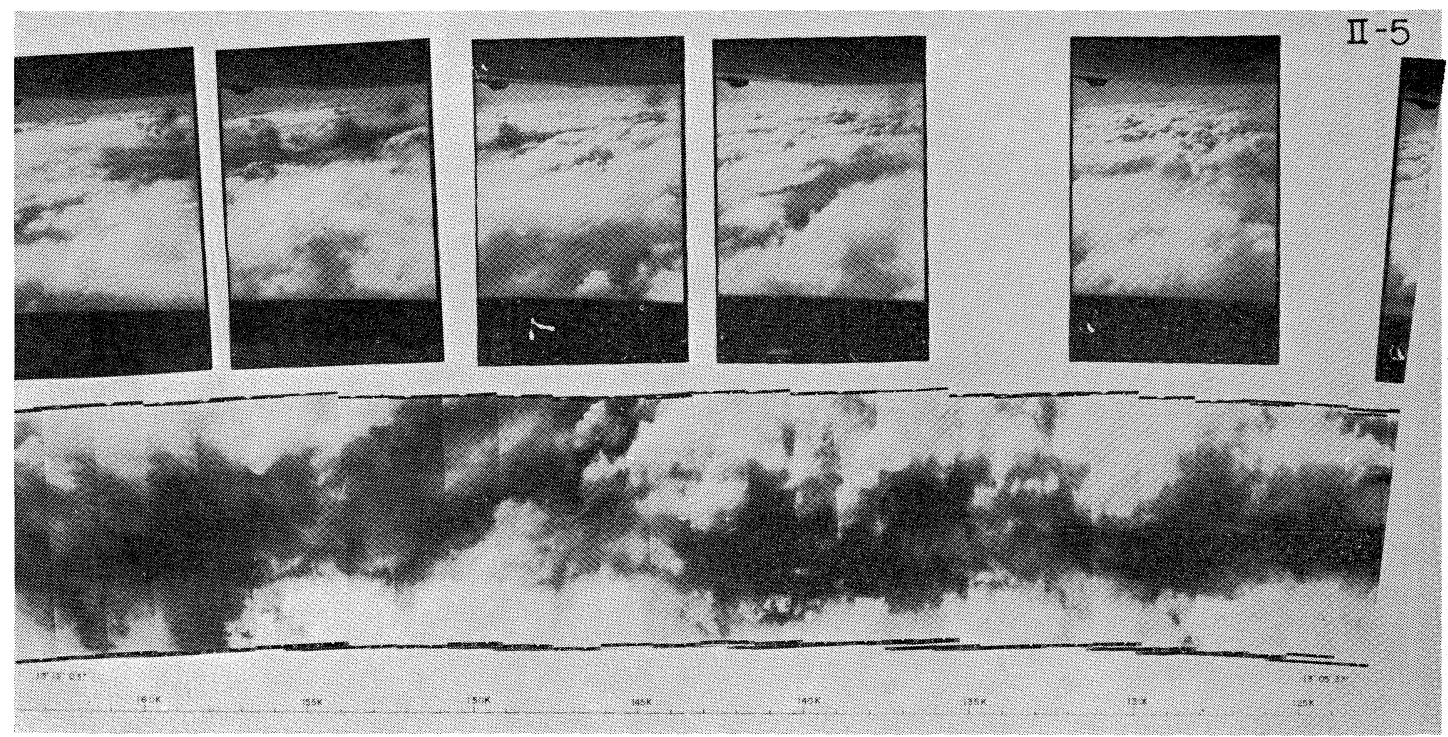

Fig. 8. Mosaic of vertical photographs taken from $13 \mathrm{~h} 05 \mathrm{~m}$ to $13 \mathrm{~h} 12 \mathrm{~m}, 2$ February 1964. High oblique photographs are shown at corresponding location. Focal lengths for both are made equal on this picture. 
As is seen from those materials, it is quite obvious that remarkable convective clouds are concentrated in a limited area. Fig. 8 shows the mosaic of vertical photographs together with high oblique photographs obtained over such area. In order to make quantitative discussion, we applied the method mentioned in the previous section to cumulus clouds appearing on vertical photographs. We picked up at a rate of 9 cloudlets for each frame covering roughly $25 \mathrm{~km}^{2}$. The heights thus obtained are averaged in every $10 \mathrm{~km}$ along the flight path and are plotted on Fig. 9 as a function of time (see also Fig. 7). Because of averaging operation, the cloud height is considerably reduced. A maximum may be found at $13 \mathrm{~h} 11 \mathrm{~m} \sim 15 \mathrm{~m}$ when the aircraft was located towards west of Noto Peninsula. But it is not certain because any identifiable cloudlets can hardly be obtained there. While other 3 maxima are noticed during the period of $13 \mathrm{~h} 20 \mathrm{~m} \sim 30 \mathrm{~m}$ at an interval of $30 \sim 40 \mathrm{~km}$.

Over convective cumulus clouds, we can find thin layer of veil-like cloud, the height of which is roughly estimated to be about $5000 \mathrm{~m}$ although the identification of cloudlet and, thus, the estimation of its height are difficult. This upper cloud layer changes its thickness (transparency) from place to place, and cumulus clouds underneath are visible through thinner layers. The thickness is also entered schematicaly in Fig. 9. The thickest upper cloud layer was found at $13 \mathrm{~h} 15 \mathrm{~m}$.

Next let us describe some results obtained from high oblique photographs. Applying the method mentioned in Section 2, we can analyze wider area of cloud distribution and cloud height. Fig. 10 shows an example with dense distribution of well developed cumulus clouds, which is obtained by analyzing 90 successive photographs. In this figure the cloud height is classified into 4 grades, i.e. less than $1500 \mathrm{~m}, 1500 \sim 3000 \mathrm{~m}, 3000 \sim 4500 \mathrm{~m}$ and more than $4500 \mathrm{~m}$. Here again towering cumulus exceeding $4500 \mathrm{~m}$ is found at $13 \mathrm{~h}$ $10 \mathrm{~m} \sim 15 \mathrm{~m}$ coinciding to the information obtained from vertical photographs (see also Fig. 9).

The number of towering cumulus which is higher than $3000 \mathrm{~m}$ amounts to 50 in a area of $150 \mathrm{~km} \times 60 \mathrm{~km} \quad(0.55$ towers per $10 \mathrm{~km}$ square). Among them, 21 cumulus are higher
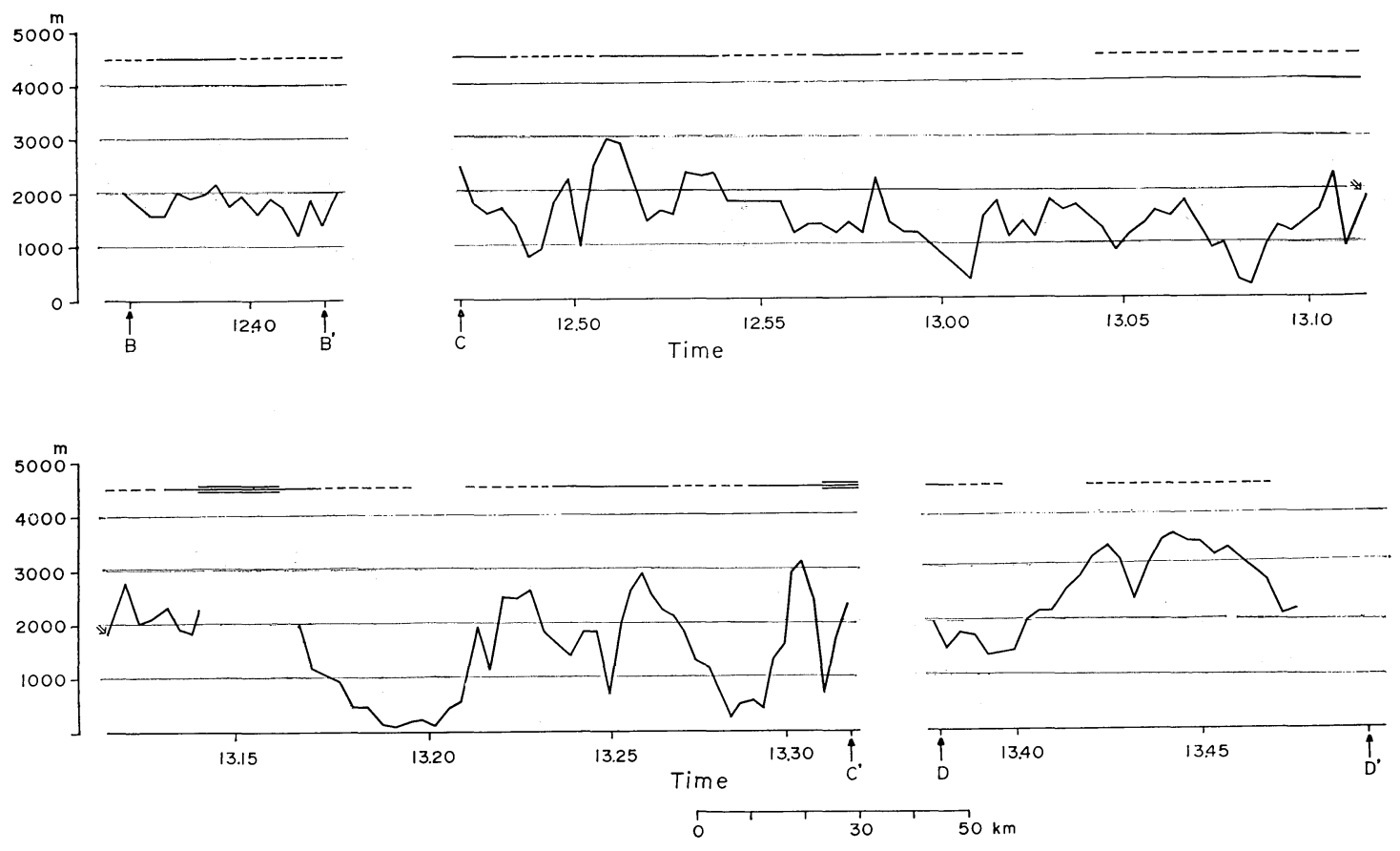

Fig. 9. The heights of cumulo-type clouds along the flight path obtained by using vertical photographs. The thickness of the veil-like high cloud is shown schematically in upper part of the figure, i.e. broken line, solid line and triple line mean thin, slightly thick and thick high cloud layer respectively. 


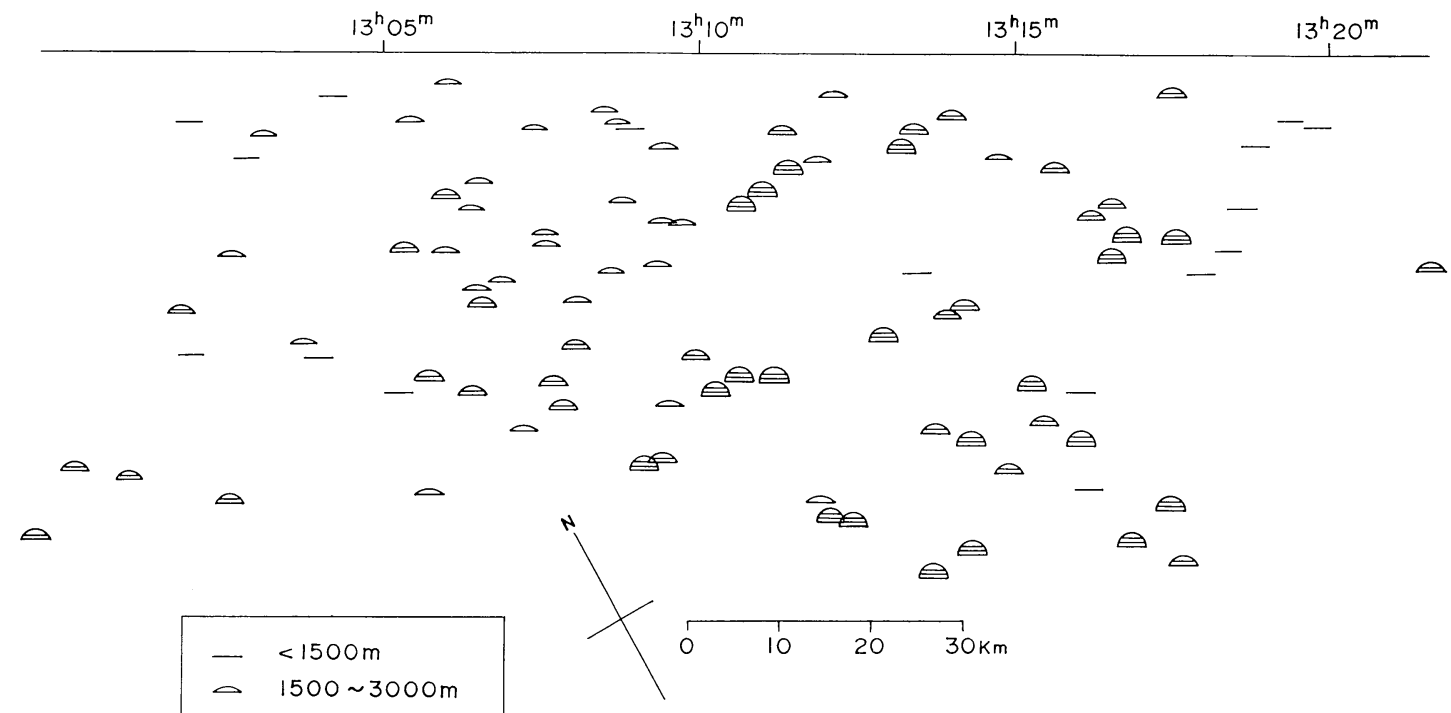

Fig. 10. The distribution of well developed cumulus clouds obtained by high-oblique photographs.

than $4500 \mathrm{~m}$, about $80 \%$ of which is located in a concentrated area of $50 \mathrm{~km} \times 60 \mathrm{~km}(13 \mathrm{~h}$ $09 \mathrm{~m} \sim 13 \mathrm{~h} 16 \mathrm{~m})$. Concentration of these towers is also as high as 0.93 per $10 \mathrm{~km}$ square.

Radar observation at Mt. Yahiko (see Fig. 7 ), on the other hand, shows a remarkable $\lambda$ shaped line echo. Figs. $11 \mathrm{a}, \mathrm{b}, \mathrm{c}$ are the radar photographs taken at $13 \mathrm{~h} 08 \mathrm{~m}, 14 \mathrm{~h} 33 \mathrm{~m}$ and $15 \mathrm{~h} 01 \mathrm{~m}$ respectively. Successive positions of this echo line are entered in Fig. 7. The echo system is composed of two lines, forward one indicated by I and following one indicated by II.

As is widely recognized, the movement of individual cells differs from phase velocity of

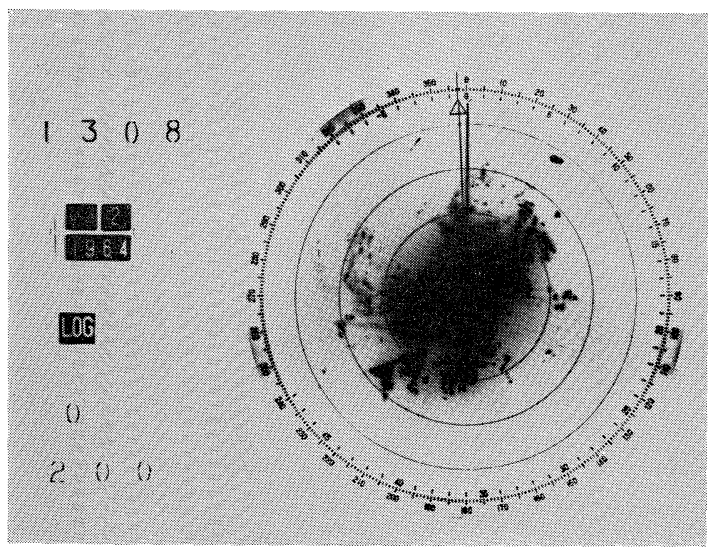

Fig. 11. (a)

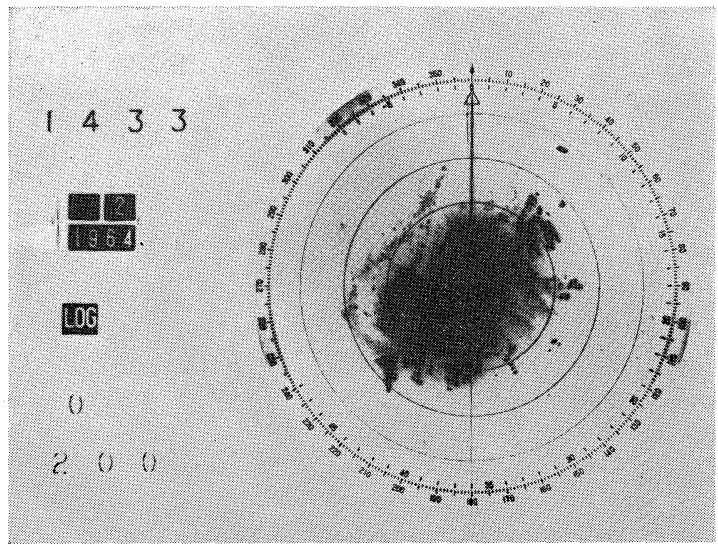

Fig. 11. (b)

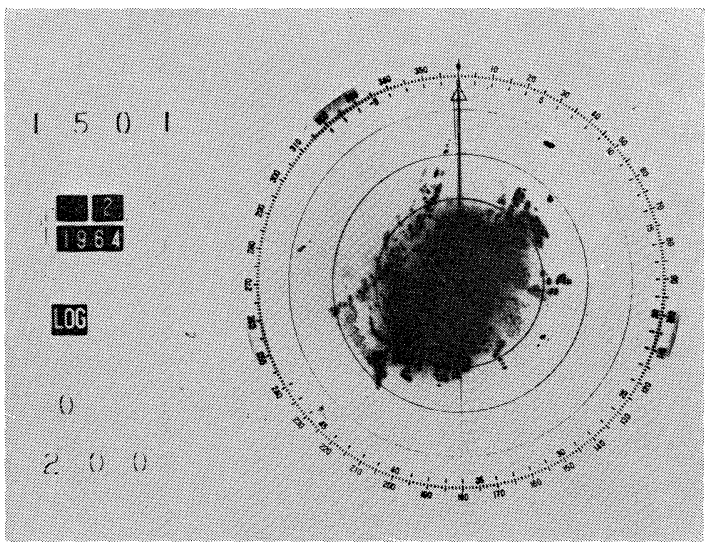

Fig. 11. (c)

Fig. 11. The radar photographs taken by Mt. Yahiko station at $13 \mathrm{~h} 08 \mathrm{~m}, 14 \mathrm{~h} 33 \mathrm{~m}$ and $15 \mathrm{~h} 01 \mathrm{~m}$. 
the system. Cells in system I and II move towards SSE with a speed of $13 \mathrm{~m} \mathrm{sec}^{-1}$ and $19 \mathrm{~m} \mathrm{sec}^{-1}$ respectively. Height of those echoes is to be approximately estimated by PPI observation from the relation between elevation angle of beam and time and distance of first appearance. It can be concluded that the echo in system $\mathrm{I}$ is higher than $3700 \mathrm{~m}$ while that in system II is lower than $3700 \mathrm{~m}$. Actual wind by rawinsonde observation at Wajima (15 JST) is given in Fig. 12. It is seen that the wind velocity has its maximum at the $800 \mathrm{mb}$ level and its minimum at the $600 \mathrm{mb}$ level. The wind direction is almost uniformly NNW. The movement of echo mentioned above shows a pretty good agreement with the actual wind at least qualitatively. If we assume that echo moves with the wind velocity, echo height is estimated to be $4 \sim 5000 \mathrm{~m}$ for system I and $2 \sim 3000 \mathrm{~m}$ for system II.

The echo system I appearing on the radar scope can be traced south-westwards as far as Noto Peninsula. While the remarkable convective area detected on high oblique and vertical photographs $(13 \mathrm{~h} 10 \mathrm{~m} \sim 13 \mathrm{~h} 15 \mathrm{~m})$ is

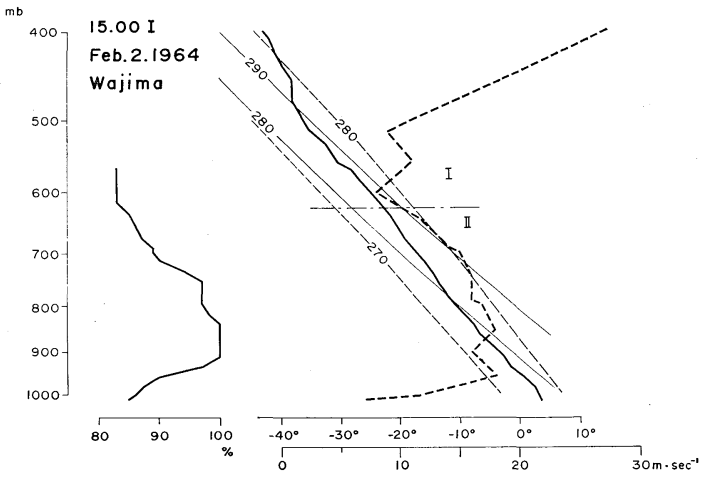

Fig. 12. Ascent curve of Wajima observation at 15 JST 2 February 1964. Full lines show temperature and humidity and broken line shows wind velocity. Thin solid line and broken line are dry and saturation adiabatic line. Chain line indicates the height separating the echo height of system I and II.

located on the further south-westward extension of system I (see Fig. 7). In other words, it can be inferred from those materials mentioned above that there existed well developed convective clouds of band structure oriented from $\mathrm{NE}$ to $\mathrm{SW}, 200 \mathrm{~km}$ in length and $30 \sim 50 \mathrm{~km}$ in width. The structure of

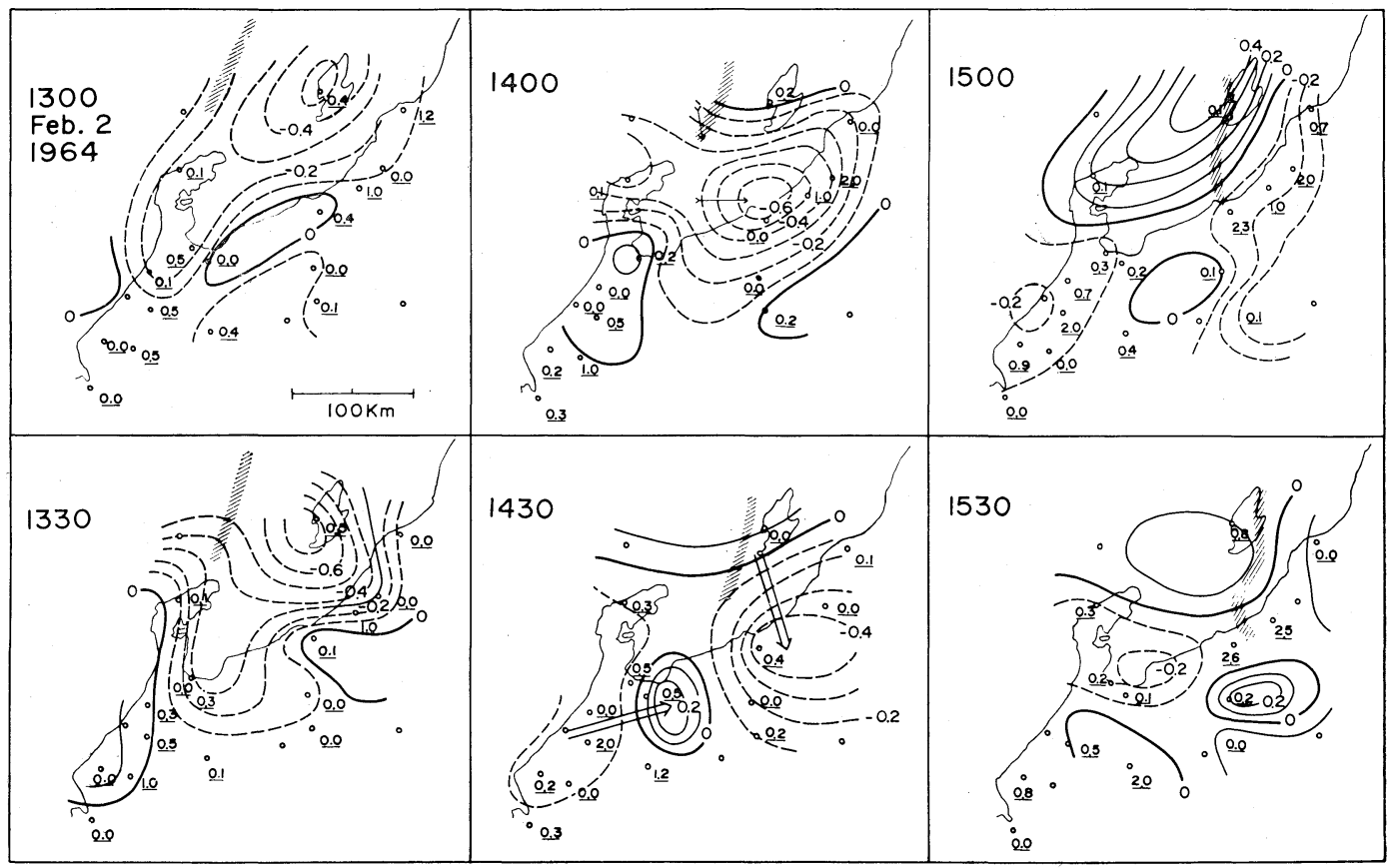

Fig. 13. Pressure anomaly from $2.5 \mathrm{hr}$ running mean labelled in every $0.2 \mathrm{mb}$. Double arrows indicate the $1 / 2 \mathrm{hr}$ displacement of pressure minimum or maximum. Hatched areas show radar echo. (after Matsumoto and Ninomiya, 1965b) 
echo system II, on the other hand, could not unfortunately be analyzed by our materials.

There seems to be no evidence that frontal structure was associated with those band echoes mentioned above. However a remarkable meso-scale disturbance is analyzed just in its vicinity, by using observations from surface network.

Fig. 13 gives a pressure anomaly distribution at $30 \mathrm{~min}$ interval obtained by operating $2.5 \mathrm{hr}$ running mean on barogram readings. The displacement of meso scale pressure disturbance is indicated by double arrows and the echo system I by hatches. Detailed discussions will be given elsewhere (Matsumoto and Ninomiya, 1965).

Finally let us see in more detail the structure of individual towering cumulus. Cloud height contour charts made by applying "multiplex" to vertical photographs are given in our project report (Heavy Snow Storm Research Group, 1965). Even though they do not necessarily represent the most developed

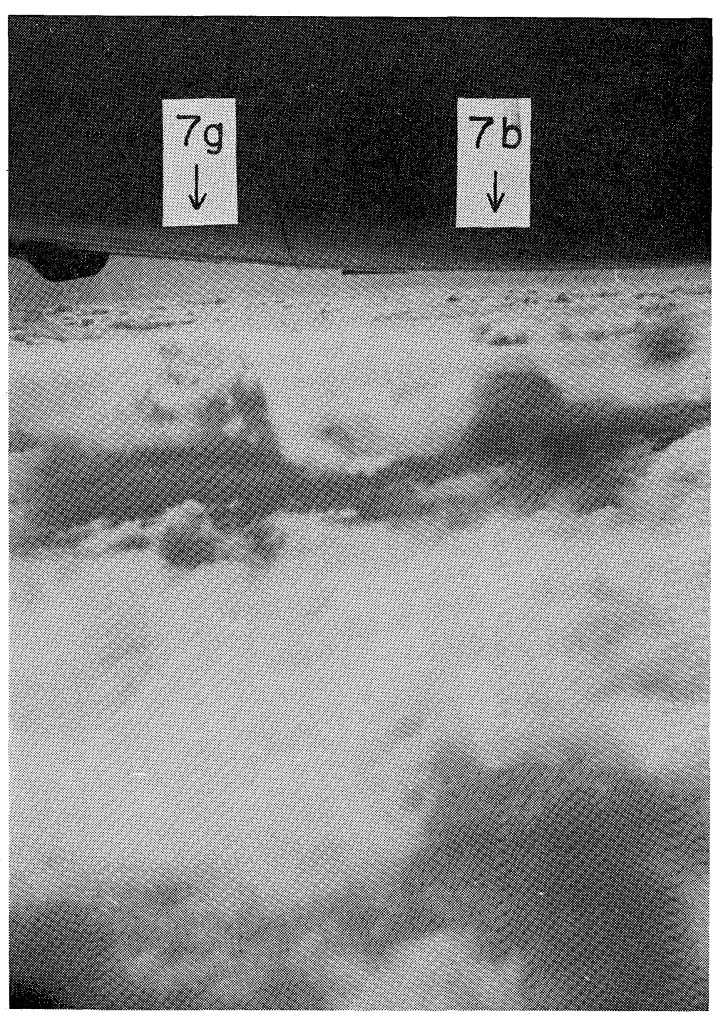

Fig. 14. A high-oblique photograph of typical towering cumuli. $7 \mathrm{~b}$ and $7 g$ are number for identify each object (see also Figs. 4 and 7 ). towering cumulus, since unfortunately the aviation could not be made but avoiding the most active convective area, we can still infer from them that convective clouds are not of single bubble structure but of complex bubble structure. Fig. 14 gives an example of high oblique photographs towering cumuli which were located at system I above mentioned. The height and dimension at $2500 \sim 3000 \mathrm{~m}$ level are estimated to be $5000 \mathrm{~m}$ and $5 \mathrm{~km}$ respectively. It penetrates the veil shaped layer of cloud at a level of $4500 \sim 5000 \mathrm{~m}$.

\section{Brief remark on synoptic weather situation}

The characteristic feature of synoptic situation is the existence of a cold dome. Fig. 15 shows the contour height of the cold dome boundary at 09 JST 2 February 1964. It is seen that the dome is located just over Hokuriku District under consideration with the maximum height of $450 \mathrm{mb}$. The threedimensional structure is quite similar to that of the cold domes which were found in January 1963 and were closely related to extremely heavy snow fall (Matsumoto et al., 1965), although it is of much smaller scale. It is just in the midst of the dome that well

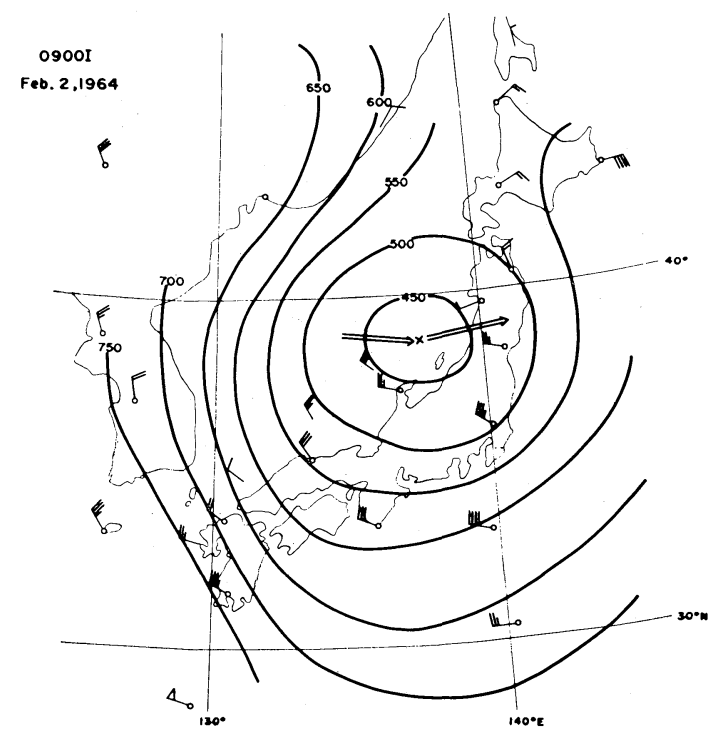

Fig. 15. Configuration of cold dome boundary labelled with $\mathrm{mb}$ height. A cross symbol indicates the position at 09 JST 2 February 1964 and double arrows show $12 \mathrm{hrs}$ displacement. Observed winds at $700 \mathrm{mb}$ level are also entered. (after Matsumoto and Ninomiya, 1965a) 
developed convective clouds were lined up in a form of band structure as was mentioned in the previous section. The maximum cloud height agrees well with the height of cold dome inversion. It should also be mentioned that any frontal systems can hardly be analyzed inside of the dome on the meridional cross section. The analyses on the cases in January 1963 (Matsumoto et al., 1965; Ninomiya, 1964) show that heavy snowfall in Hokuriku District was observed at the time of passage of cold domes (or cold vortices). In this respect, the observations discussed above reveal some features of active convective clouds which should be related to heavy snowfall. The surface pressure field and weather distribution are given in Fig. 16 and Fig. 17 respectively. On both figures, the cold dome contour is entered. It is clearly seen that cumulus activities and a considerable amount of snowfall were observed in the central region of cold dome where the stratification is unstable because of the heating from sea surface (Matsumoto et al., 1965).

Aerophotographic surveys of snow cloud have already been made 3 times. Among

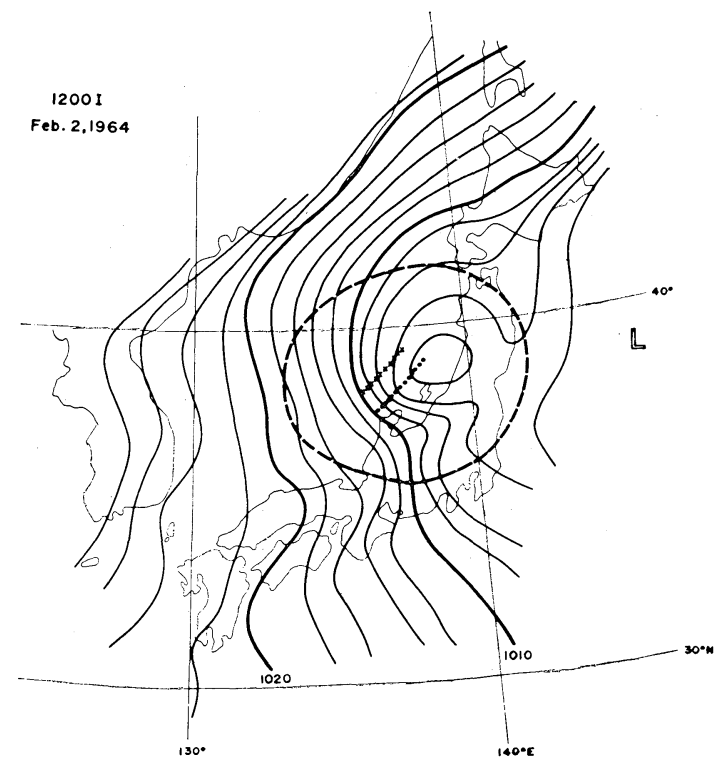

Fig. 16. Surface pressure distribution at 12 JST 2 February 1964. Cold dome boundary at 500 $\mathrm{mb}$ level is reproduced from Fig. 15 (broken line). Cross symbols indicate the echo system II and small circles indicate pressure minimum line of meso system. (after Matsumoto and Ninomiya, 1965b)

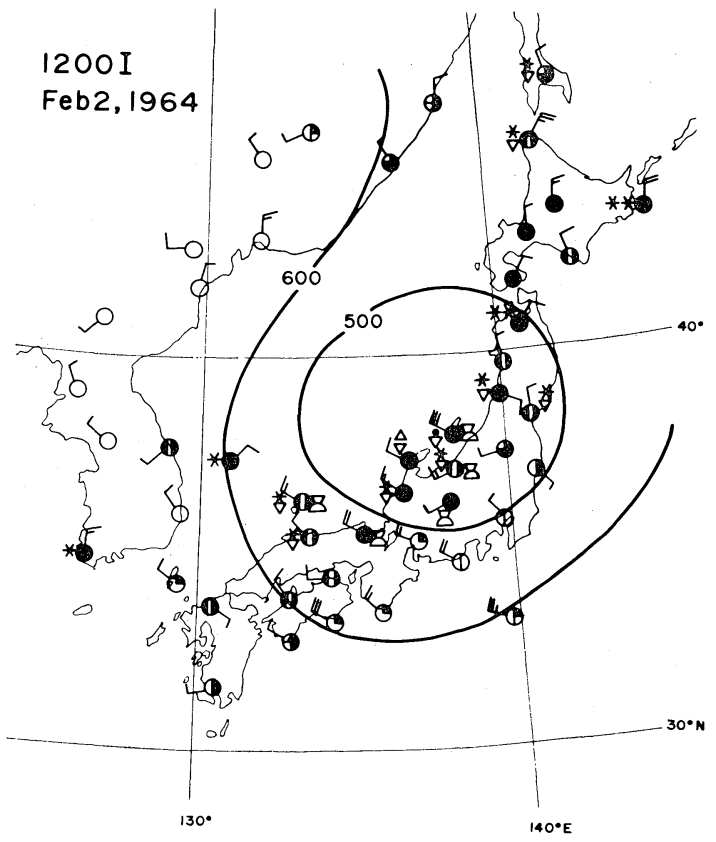

Fig. 17. Weather distribution and cold dome contour. Quoted after Matsumoto and Ninomiya (1965b)

them, Asai $(1964,1965)$ analyzed the cases of 20 January 1963 and 3 February 1964 with typical band structure of lower convective clouds. Cold dome situation was not associated with both cases and the cloud height did not exceed $2 \sim 3000 \mathrm{~m}$. On the other hand, our case described here and other case for example of 18 January 1963 were related to heavy snow situation in the vicinity of cold dome center. RECCO flight made by US Air Force in 18 January 1963, reported the existence of towering cumulus reaching $20000 \mathrm{ft}$ height in the area where smaller scale disturbance is probably developing (unpublished report by Ninomiya and Akiyama).

\section{Conclusion}

The method of cloud analysis by using the aerophotographic observation data has just been developed. Some analyses in the past were done rather subjectively or under unnatural assumptions and were subject to many kinds of error sources due to inaccuracy of positioning, steering and camera mounting etc. As a first step to establish objective method of analysis, we apply the least square technique on a single object cloud which 
moves on the successive image planes and obtained the location and the height of cloud under consideration with higher accuracy. Here we made assumptions concerning the movement of cloud and azimuth of optical axis which are to be verified indirectly by some other informations.

The distribution of clouds thus obtained is closely related to the echo line observed by a radar, which developed in the vicinity of the core of cold dome and brought considerable amount of snowfall. Very high winter time convective clouds exceeding $5000 \mathrm{~m}$ were found there. This is in good agreement with the fact that the air inside a cold dome is usually almost saturated and moist adiabatically unstable and the height of central part is higher than the $500 \mathrm{mb}$ level. After the passage of such cold vortex, outburst of the northwest monsoon takes place. In those circumstances, a remarkable inversion layer is usually found at about the $8 \sim 700 \mathrm{mb}$ level and the cloud height is correspondingly lower over the Japan Sea.

\section{Acknowledgments}

The authors express their hearty thanks to Dr. K. Takahashi and the staff members of Tokyo District Observatory for their encouragements and the member of Heavy Snow Storm Research Group, MRI for their discussions. Thanks are also due to Higashi Nihon Koku Co., for carring out chartared flight under some difficult conditions, to Miss T. Akiyama, Miss H. Imai and Miss K. Fukazawa for their helps in computation and drafting.

\section{References}

Asai, T., 1964: Photographic observation of clouds by aircraft during snowfall period in Hokuriku District. J. meteor. Soc. Japan, Ser. II, 42, 186-196.
Asai, T., 1965: Cloud bands over the Japan Sea off Hokuriku District during a cold air outburst. (to be published).

Fujita, T. and H.R. Byers, 1960: Model of hail cloud as revealed by photogrammetric analysis. Tech. Rep. No. 3, Univ. of Chicago, 9pp.

Fujita, T., 1963: A technique for precise analysis for satellite data; volume 1-photogrammetry. Meteorological Satellite Laboratory Report No. 14, U.S. Weather Bureau, 106pp.

Heavy Snow Storm Research Group, 1965: Aerophotographic observation of cloud over the coastal area of the Japan Sea in winter of 1964. Papers in Meteor. and Geophys., 15, 216-228.

Malkus, J.S., C. Ronne and M. Chaffee, 1961 : Cloud patterns in hurricane Daisy 1958. Tellus, 13, 8-30.

Malkus, J.S. and H. Riehl, 1964: Cloud structure and distributions over the tropical Pacific Ocean. Tellus, 16, 275-287.

Matsumoto, S. et al., 1965: Behavior of the extraordinary cold vortex over the Far East coastal area observed during the period from 22 January to 24 January, 1963. J. meteor. Soc. Japan, Ser. II, 43, 100-115.

Matsumoto, S. and K. Ninomiya, 1965a: On the analysis of a cold vortex with steady eastward movement to be published in Papers in Meteor. and Geophys.

Matsumoto, S. and K. Ninomiya, 1965b : Meso-scale disturbance observed in the vicinity of a cold vortex center to be published in Papers in Meteor. and Gephys.

Merritt, E. L., 1958: Analytical photogrammetry. Pitman publishing corporation. 242pp.

Meteorological Research Institute, 1964: Data of the Heavy Snow Storm Project observation for the winter 1963-1964. Meteorological Research Institute, Tokyo.

Ninomiya, K., 1964: Water-substance budget over the Japan Sea and the Japan Islands during the period of heavy snow storm J. meteor. Soc. Japan, Ser. II, 42, 317-329.

Watanabe, K., 1961: On the theory and technique of an easy method of wide range photogrammetry for the observations of sea ice distri. bution. Oceanographic Mag., 12, 77-121. 


\title{
コールド・トーム中心付近に観測される対流雲の航空写真観測
}

\author{
松本誠一・宮 洸三
}

気象研究所

1964 年 2 月 2 日, 北陸沿岸で観測された顕著な中規模擾乱の解析飞, 航空写真測量観測を適用した。

本論文は 2 つ部分より成るが, 前半には雲の解析のためと航空写真測量法を改善し, これを対流雲分布の解析に 応用した結果を述へててる。この手法はレーダー観測と同様に，中規模現象の解明に有力な手段となることが分かっ た。

中規模擾乱域内には，冬期にもかかわらず高さ $5000 \mathrm{~m}$ 以上の非常に活発な積雲対流が存在することがたしかめら れた。この擾乱はコールド・ドーム中心付近に発達したものである。

なお, 本研究は気象研究所北陸豪雪の研究の一部として行なわれたものである。 